\title{
Neogeography and the delusion of democratisation
}

Mordechai (Muki) Haklay

Department of Civil, Environmental and Geomatic Engineering

UCL

Gower St., London, WC1E 6BT

United Kingdom

m.haklay@ucl.ac.uk 


\section{Neogeography and the delusion of democratisation}

\section{Abstract}

Within the academic and popular discussion of neogeography, it is routinely argued that the process of producing and using geographical information has been fundamentally democratised. Neogeography, in contrast to 'established geography', especially uses the argument that it is for anyone, anywhere and anytime. Similar arguments have been used to praise the growth in Web GIS since the mid-1990s and seem to be persistent in the conceptualisation of these technologies. However, what is the nature of this democracy, and to what extent do the technologies that are used in neogeography fulfil this democratisation promise?

In this contribution, the framework offered by Andrew Feenberg in his critical theory of technology, and especially his call for 'deep democratisation', is used to provide a critique of these assertions of the nature of neogeography. The analysis shows that, unlike early critical GIS and the literature on participatory GIS, the analysis of neogeography adopted an instrumentalist interpretation of the technology and its applications. This view claims that technology is value-free and there is a separation between means and ends. This type of argument ignores and disguises the values that are integrated inexorably in advanced technologies. Once the values are exposed and discussed, neogeography becomes far less exciting and transformative. It becomes clearer that there is a separation between technological elite and a wider group of uninformed, labouring participants who are not empowered through the use of the technology. There are also multiple obstacles that limit the democratic potential of neogeography.

The analysis progresses by considering the hierarchy of hacking, understood here as the ability to alter and change the meaning and use of a specific technological system. This hierarchy further explains the democratisation potentialities and limits of neogeography. Because of the reduced barriers, neogeography does offer some increased level of democratisation but, to fulfil this potential, it requires careful implementation that takes into account social and political aspects.

Keywords: democratisation, neogeography, Participatory GIS, Philosophy of Technology, Deep Democratisation, hacker culture

\section{Introduction}

Since the emergence of the World Wide Web (Web) in the early 1990s, claims about its democratic potential and practice are a persistent feature in the discourse about it. While awareness of the potential of 'anyone, anytime, anywhere' to access and use information was extolled for a long while (for an early example see Batty 1997), the emergence of Web 2.0 in the mid-2000s (O'Reilly 2005) increased this notion. In the popular writing of authors such as Friedman (2006), these sentiments are amplified by highlighting the ability of anyone to 'plug into the flat earth platform' from anywhere and anytime. 

45(1), 55 - 69 doi:10.1068/a45184

Around the middle of the decade, the concept of neogeography appeared and the ability to communicate geographic information over the Web (in what is termed the GeoWeb) gained prominence (see Haklay et al. 2008). Neogeography increased the notion of participation and access to geographic information, now amplified through the use of the political term democratisation. The following citations provide a flavour of the discourse within academic and popular writing - for example, in Mike Goodchild's declaration that 'Just as the PC democratised computing, so systems like Google Earth will democratise GIS' (quoted in Butler 2006), or Turner's (2006) definition of neogeography as 'Essentially, Neogeography is about people using and creating their own maps, on their own terms and by combining elements of an existing toolset. Neogeography is about sharing location information with friends and visitors, helping shape context, and conveying understanding through knowledge of place'. This definition emphasises the wide access to the technology in everyday practice. Similar and stronger statements can be found in Warf and Sui (2010) who clarify that 'neogeography has helped to foster an unprecedented democratization of geographic knowledge' (p. 200) and, moreover, 'Wikification represents a significant step forward in the democratization of geographic information, shifting control over the production and use of GIS data from a handful of experts to large groups of users' (ibid.). Even within international organisations this seems to be the accepted view as Nigel Snoad, strategy adviser for the communications and information services unit of the United Nations Office for the Coordination of Humanitarian Affairs (OCHA), stated: 'On the technology side, Google, Microsoft and OpenStreetMap have really democratized mapping' (cited in Lohr 2011).

However, what is the nature of this democratisation and what are its limits? To what extent do the technologies that mediate the access to, and creation of, geographic information allow and enable such democratisation?

To answer these questions, we need to explore the meaning of democratisation and, more specifically, within the context of interaction between people and technology. According to the Oxford English Dictionary, democratisation is 'the action of rendering, or process of becoming, democratic', and democracy is defined as 'Government by the people; that form of government in which the sovereign power resides in the people as a whole, and is exercised either directly by them (as in the small republics of antiquity) or by officers elected by them. In modern use often more vaguely denoting a social state in which all have equal rights, without hereditary or arbitrary differences of rank or privilege' [emphasis added]. A more colloquial notion of democratisation, and a much weaker one, is making a process or activity that used to be restricted to an elite or privileged group available to a wider group in society and potentially to all. For example, with mobile telephony now available across the globe, the statement 'mobile telephony has been democratised' aims to express the fact that, merely three decades ago, only the rich and powerful members of Western society had access to this technology.

Therefore, it is accepted from the start that the notion of democratisation cited above is more about the potential of neogeography to make the ability to assemble, organise and share geographical information accessible to anyone, anywhere and anytime and for a variety of purposes than about advancing the specific concept of democracy. And yet, it will 
be wrong to ignore the fuller meaning of the concept. Democratisation has a deeper meaning in respect of making geographic information technologies more accessible to hitherto excluded or marginalised groups in a way that assists them to make a change in their life and environment. Democratisation evokes ideas about participation, equality, the right to influence decision making, support to individual and group rights, access to resources and opportunities, etc. (Doppelt 2006). Using this stronger interpretation of democratisation reveals the limitation of current neogeographic practices and opens up the possibility of considering alternative development of technologies that can, indeed, be considered as democratising.

To explore this juncture of technology and democratisation, this paper relies on Andrew Feenberg's critical philosophy of technology, especially as explored in his Questioning Technology (1999) and Transforming Technology (2002), which is useful as he addresses issues of democratisation and technology directly. For readers who are not familiar with the main positions within philosophy of technology, a very brief overview - based on Feenberg's interpretation (1999) - is provided. This will help to explain his specific critique and suggestion for 'deep democratisation' of technology.

Equipped with these concepts, attention is turned to the discussion about the democratic potential of Geographic Information Systems (GIS), which appears in early discussions about GIS and society in the 1990s, and especially to the discussions within the literature on (Public) Participatory GIS (PPGIS/PGIS - assumed to be interchangeable here) and critical GIS. As we shall see, discussions about empowerment, marginalisation and governance are central to this literature from its inception and provide the foundations to build a deeper concept of democratisation when considering neogeographic practices.

Based on this historical understanding, the core of the paper explores why it is that neogeographic practices are assumed to be democratising and, more importantly, what the limitations are on their democratic potential. To do that, a hierarchy of 'hacking' - that is the artful alteration of technology beyond the goals of its original design or intent - is suggested. Importantly, here 'hacking' does not mean the malicious alteration of technology or unauthorised access to computer systems, or the specific culture of technology enthusiasts ('hacker culture'). The term is used to capture the first and second instrumentation that Feenberg $(1996,2002)$ describes. As we shall see, by exploring the ability to alter systems, there is some justification in the democratisation claims of neogeography as it has, indeed, improved the outreach of geographic technologies and opened up the potential of their use in improving democratic processes, but in a much more limited scope and extent. The paper concludes with observations on the utilisation of neogeographic technologies within the participatory process that aim to increase democratisation in its deeper sense.

For the rest of the discussion, the term 'neogeographic technologies' is used to describe the technological assemblage of systems that facilitate the neogeography practice - from cameras that record the location from which a picture is taken, to online mapping systems that allow users to add geographic details to them, to places where they can visualise or share the information that they have captured. 


\section{Philosophy of technology and its main schools of thought}

As outlined above, the aim of this section is to introduce an unfamiliar reader to the main positions in thinking about technology and society that are common within the philosophy of technology, so as to introduce some of the core concepts that will be used in the current analysis. For a more comprehensive exploration of philosophy of technology, see Dusek (2006), as well as Scharff and Dusek (2002).

Technology became a focus of scholarly studies and discussion only during the final years of the $19^{\text {th }}$ century (Dusek 2006). Most of the ideas that are now influencing the philosophy of technology were developed during the $20^{\text {th }}$ century, and among the notable contributors to this discussion are Martin Heidegger, Herbert Marcuse, John Dewey and Lewis Mumford (Feenberg 1999). Even the word 'technology' gained its current sense only at the beginning of the $20^{\text {th }}$ century (Marx 1999). Only since the 1970s has technology received concrete philosophical attention with the growth of the philosophy of technology, and, as Feenberg (1999) noted, 'the human significance of technology is largely unmapped territory' (p. 1).

Feenberg (1999) identified four main streams of thought on the essence of technology and its linkage to society (Figure 1). These are instrumentalism, determinism, substantivism and critical theory. The deterministic view follows the ideas of Karl Marx and Charles Darwin, assuming that technology is actually a force of its own with evolution that, while carried out by humans, by and large is not dependent on them. If one group of humans doesn't develop a specific technology, another will. It can be encapsulated as the view that technological progress supports humanity's march to freedom and happiness. Technology is also viewed as neutral as it provides a means that can be used for any purpose. Hence, technology is an extension of nature and outside the political realm.

By the 1940s and 1950s, another view emerged: the substantive view developed once it became clear that technology has political implications. Though still perceived as autonomous, technology is not viewed as a neutral force but as a force that embodies specific values such as control over labour and resources, and a notion of efficiency that is mostly about maximising economic output. The technologies that we use shape modern life. Thus, it is impossible to separate means from ends. The way we do things determines who and what we are. Martin Heidegger and, more pronouncedly, Jacques Ellul (1964) are two of the prominent advocates of the substantive view. This view became especially popular during the 1960s and 1970s as the results of technological development, such as the atom bomb, became apparent and a certain dystopian view of the impact of technology gained attention.

The same period marks the emergence of a third view based on critical theory. In the first years of this theoretical development, Herbert Marcuse and Michel Foucault stand out as critics of scientific ideologies and technological determinism. They do not accept the unilinear path of technology, but argue that technological progress is shaped by social control. At the same time (inconsistently) they argue that modern forms of social control and domination are essentially technical. Using Feenberg's (1999) terms, this view is 'left dystopian' and is influenced by the substantivists. 


\section{5(1), 55 - 69 doi:10.1068/a45184}

This critical view of technology is dominant in current studies of technology. In the last 20 years, the ideas in science and technology studies (Latour 1993, 1996) on the nature of scientific projects have gained ground and the critical approach has evolved into constructivism. According to this view, technology must be studied and understood as an integral part of society. Technological projects do not have a single, clear path from inception to production, but multiple routes and directions. The success of any given technology does not lie with superior design or efficiency, but in the social context and support that it receives. The process of creating technological artefacts is socially constructed until 'closure' happens, in which the specific technology becomes fixed. Once closure happens, the technology becomes a 'black box' and the social negotiations that accompany its creation are forgotten.

The final position is the instrumentalist view, which, while accepting that technology is not autonomous, still separates means from ends. Technology by itself does not encapsulate values, and it is the way in which it is applied that gives it its social meaning. The instrumentalist view is common today and has a wide range of supporters. Negroponte (1995) and Friedman (2006) both praise the inherent capabilities of digital technologies to improve the quality of life and society in general, and do not see any values that are integral to it. It is also the common view among technology enthusiasts (as any occasional reading of Wired or The Economist will reveal).

The four main positions are presented in Figure 1.

\begin{tabular}{|l|l|l|}
\cline { 2 - 3 } \multicolumn{1}{l|}{ Technology is: } & Autonomous & Humanly controlled \\
\hline $\begin{array}{l}\text { Neutral } \\
\text { (Means and Ends are } \\
\text { separated) }\end{array}$ & $\begin{array}{l}\text { Determinism } \\
\text { (Traditional Marxism, } \\
\text { Darwinistic explanations) }\end{array}$ & $\begin{array}{l}\text { Instrumentalism } \\
\text { (Liberal view of } \\
\text { technological progress) }\end{array}$ \\
\hline $\begin{array}{l}\text { Value-laden } \\
\text { (Means and Ends cannot } \\
\text { be separated) }\end{array}$ & $\begin{array}{l}\text { Substantivism } \\
\text { (Ellul, Heideggar) }\end{array}$ & $\begin{array}{l}\text { Critical Theory } \\
\text { ('Left dystopian', } \\
\text { constructivism) }\end{array}$ \\
\hline
\end{tabular}

Figure 1 - Technology and Society: main theoretical frameworks (after Feenberg 1999)

These classes represent 'ideal types' of thought, usually associated with a specific writer. For example, and as noted, Jacques Ellul is associated with the substantive view. In The Technological Society (1964) Ellul gives a bleak account of the influence of technology on humanity. He views technology as an unstoppable force that is taking over society and impacts every aspect of life. The only solution that he provides is the spiritual transition of humanity. However, in practice, it is more difficult to link a person or writing to a specific view but rather to locate it somewhere in the continuum between the different positions, although it must be noted that, outside technology studies, the instrumentalist view is the most dominant within current social science (Feenberg 2002). 


\section{Feenberg's critical theory of technology}

Within the critical philosophy of technology, Feenberg's theory is one of the more comprehensive and detailed (Veak 2006). He developed and advanced it through several books in the 1990s, culminating in Questioning Technology (1999), Transforming Technology (2002) and a collection of articles that discuss the theory in Democratizing Technology (Veak 2006). Feenberg's view is constructivist: that is, emphasising that technology development is humanly controlled and encapsulates values and politics, thus it should be open to democratic control and intervention.

At the core of his approach is the idea that technology can be used to the betterment of life conditions and society in general by carefully and rationally choosing technological paths that take into account the various interests and needs of a wide range of groups in society in a democratic way, and by that he means taking into account the concerns and needs of society as a whole. Many science and technology studies, such as Latour's (1996), have demonstrated that technology is not created with a single set of values, but through negotiation of multiple actors and conflicting interests. Therefore, technology can and should be seen as a result of political negotiations that lead to its production and use. In too many cases, the complexities of technological systems are used to concentrate power within small groups of technological, financial and political elites and to prevent the wider body of citizens from meaningful participation in shaping it and deciding what role it should have in the everyday.

Feenberg highlights that technology encapsulates an ambivalence between the 'conservation of hierarchy', which most technologies promote and reproduce hence the continuity in power structures in advanced capitalist societies despite technological upheaval, and 'democratic rationalisation', which are the aspects of new technologies that undermine existing power structures and allow for new opportunities by marginalised or ignored groups to assert themselves. Feenberg notes that technical codes always encapsulate significant social values such as efficiency or capitalism, and that these technical codes seem to circularly use the meaning that objects and technical process acquired through society (which are emphasising these values) to affirm and stabilise this specific meaning. In so doing, technical codes seem 'self-evident' and unproblematic. Importantly, 'Technical representation is not primarily about the selection of a trusted personnel, but involves the embodiment of social and political demands in technical codes' (1999, p. 142).

Based on this understanding, Feenberg calls for a 'deep democratisation' of technology, which can be achieved through the integration of democratic rationalisation of technical codes, combined with a deliberate democratic control over technical institutions: 'such deep democratization would alter the structure and knowledge base of management and expertise. The exercise of authority would come to favour agency in technically mediated social domains. Deep democratization promises an alternative to technocracy. Instead of popular agency appearing as an anomaly and an interference, it would be normalized and incorporated into the standard procedures of technical design' (1999, p. 147).

Feenberg offers a useful analytical framework as a way to understand technology differentiates between primary and secondary instrumentation $(1999,2006)$. Primary 
instrumentation focuses on the functional aspects such as separating objects from their wider everyday or regular use context to make it possible to turn them into technological artefacts, or the reduction of any 'unwanted' characteristics that cannot be part of automated and easily controlled technology. Secondary instrumentation, on the other hand, opens up the ability of social intervention, as this is the process through which technology is constituted into specific social and environmental contexts. Notice that primary and secondary instrumentations do not happen separately, but happen at the same time for any given technology. Thus, Global Positioning System (GPS) receivers are created with concepts of efficiency, accuracy and consumerism but enrol into a specific context of use in which participants might use them in conjunction with mobile phones and software application to assert control over another person and create 'geoslavery' (Dobson and Fisher 2003) or, in the context of play, in the practice of geocaching where participants use them to locate 'hidden treasures'.

Feenberg's theory provides a powerful critique of the instrumentalist view of technology, which assumes the separation of means from ends, and therefore claims that technology by itself is value-free and outside the realm of political negotiation and social influence. The analysis of technological ambivalence highlights how technological codes are created in a 'common-sense' approach that hides their social, ethical, moral and environmental implications. Once the technical code is stabilised, society is expected to accept technology the way it is without questioning it. Yet, if we accept that all technologies have politics, the instrumentalist view turns out to be one of the mechanisms through which existing power structures are maintained and reproduced.

The set of concepts from the philosophy of technology in general, and Feenberg's theory in particular, will help in the analysis of the nature of neogeography and its associated technologies. The first issue is to notice a fundamental difference between the literature about neogeography and that of critical GIS and PPGIS. As we shall see, while the former is mostly supporting the instrumentalist view of technology, the latter is well within the critical perspective of technology.

\section{Democratisation in neogeography versus participatory and critical GIS}

Feenberg's suggestion for deep democratisation, ideally at the primary and secondary instrumentation levels, chimes with many of the discussions that appeared within the literature on participatory GIS and critical GIS. Historically, PPGIS/PGIS, or the opening of engagement with GIS to larger groups of users and using it for community-centred activity while noticing how it is embedded within existing social and political structures and processes, was first to emerge from the discussion on 'GIS and Society' in the mid-1990s. Critical GIS, which followed suit, focused on issues of representation, meaning and the consequences of digital representation on social knowledge and power (Elwood 2008). While in some contexts it is useful to maintain the differentiation between these fields of study, for the sake of the discussion here, especially because of the focus on democratisation in this paper, attempting to delineate the subtle differentiations between these areas can lead to further confusion. From the point of view of interpreting technology 
as humanly controlled and open to social interventions, both PGIS and critical GIS belong to critical theory of technology and therefore will be explored together.

From its inception, the literature on PGIS and critical GIS was explicit about the sense in which the tools should serve social purposes. The publication of Ground Truth (Pickles 1995a) is recognised as an important milestone in the evolution of these areas of study. The final two chapters are the precursors of PGIS/PPGIS (Harris et al. 1995) and critical GIS (Pickles 1995b) and both discuss the need to include 'deep' democratisation in the application of GIS, with Harris et al. (1995) explicitly calling for applications that are 'broadbased, inclusive, gender-sensitive, and biased towards marginalised people' (p. 218). In another early paper, originally from a meeting dedicated to the empowerment and marginalisation power of GIS in 1998, Leitner et al. (2002) highlight the need to consider how the use of GIS can impact democratic process inside community organisations, and not only within the wider political system, as well as noticing how the technology itself can lead to changes in priorities of various organisations. The literature that followed included extensive discussion of the democratisation potential of information when used to assist marginalised communities (Sawicki and Craig 1996) and the political and governance implications of PGIS practices (Ghose 2001, 2007; Elwood 2002; McCall 2003). For a wider discussion see Sieber (2006), O'Sullivan (2006) and Elwood (2008).

Against this rich engagement with the deeper issues of democratisation, discussions about neogeography seem to focus on the instrumentalist understanding of technology. One of the early examples of academic writing that highlights the importance of neogeographic practices is provided by Miller (2006) who takes a functional approach to the concept of GIS/2 (Schroeder 1996) and argues that Google Maps mashups provided all the necessary functionality - as demonstrated during the response to the Hurricane Katrina disaster while the discussion about the concept for over a decade failed to achieve what Google Maps successfully implemented. What Miller fails to notice is that GIS/2 was never about functionality. Even when Sieber (2004) was arguing for the possibility of rewiring GIS to make it closer to the GIS/2 concept, she was not discussing the technology but, rather, aspects of empowerment: providing the tools that will allow increased control over the technology by those in disadvantaged and marginalised positions in society. As noted, this understanding of PGIS and critical GIS as a social practice is central to the understanding of the role of technology within specific contexts.

In contrast, neogeography is mostly represented in a decontextualised way as the citation in the introduction from Turner's Introduction to Neogeography demonstrates - it does not discuss who the people are that benefit and if there is a deeper purpose, beyond fun, for their engagement in neogeography. Goodchild's work on Volunteered Geographic Information (VGI) is also represented in a value-free manner - for example, the closing sentences of his seminal 2007 paper state: 'Moreover, such volunteering appears to provide the only feasible solution to... the supply of geographic information worldwide... But 6 billion citizen observers, equipped with the means to upload their observations, could provide a very effective replacement. The willingness to do so is clearly there, as is the technology to integrate their inputs.' (p. 31). Importantly, VGI is more concerned with the data and less with the process. However, as the Goodchild and Turner discussion (Wilson 
and Graham, this issue) demonstrates, the containment relationships between VGI and neogeography are far from simple and there is a significant overlap.

It is wrong to state that all writing about neogeography adopts the instrumentalist view wholeheartedly, as there are examples of critical approaches to the technology such as Graham's (2010) analysis of the construction of place, Crutcher and Zook's (2009) analysis of the inequality in neogeographic coverage of New Orleans post-Katrina or Elwood's (2008) discussion of VGI from a critical GIS perspective. However, these interventions are limited in their scope and it is telling that Elwood herself, in her review of neogeography and VGI (2009), only briefly discusses issues of empowerment, participation and marginalisation although this is rectified in her 2010 review. Warf and Sui (2010) who are cited above with regard to the use of the term 'democratisation' also view neogeography as 'active bilateral contacts between the producers and analysts of geographic data, resulting in a constantly mutating body of work, usually without a clearly defined political agenda' (p. 200, emphasis added), while noticing the social ambivalence in its practices and highlighting some of its secondary instrumentation.

Despite these caveats, which are relevant in the academic discussion about neogeography, it is important to notice that the corporations, technology start-up companies and technology enthusiasts that are creating the neogeographic landscape are all adopting the instrumentalist point of view, while ignoring the deeply embedded values (Bellamy-Foster and McChesney 2011).

In summary, the instrumentalist approach is central to the development and practice of neogeography. The user is viewed as a free agent who makes their own informed decisions about the use of a system and can put it to use to promote their own goals, while being able to consider the full context of its use. Because there is nothing that prevents anyone, anytime and anywhere and for any purpose from using the system, democratisation has been achieved. Given this analysis, what can we learn about the democratisation of geographic information by examining the observed characteristics of neogeography?

\section{The reality of neogeography and democratisation}

There are many empirical reasons to reject the claim for democratisation and the recurring theme of 'anyone, anywhere, anytime'. Such reasons include the differential access to computers and communication, which is an ongoing theme about the Web (USDOC/NTIA 1999, Castells 1996), and, even today, only $70 \%$ of UK households have access to the Web; more importantly, many of the remaining households do not see the benefit in joining online (PwC 2009). Beyond this, there is secondary digital exclusion (Hargittai 2002), which relates to the skills and abilities of people to participate in online activities beyond rudimentary browsing.

So much for 'anyone', but also the 'anywhere' should be questioned - differential access to the Web exists between large urban centres and rural communities (Bellamy-Foster and McChesney 2011) to the degree that the UK government had to enact a special law (Digital Economy Bill) to try to tackle the failure of broadband access across the country. The issue of access is compounded by the prohibitive costs of 'data roaming' charges, levied by mobile 
network operators, which make the use of mobile Web access expensive exactly at the time when a user is likely to explore new places and use neogeographic tools.

There are further issues that empirical observations highlight about the limits of democratisation of neogeographic practices. Participation inequalities (Nielsen 2006) have been demonstrated in many user-contributed systems with very few contributing a lot and many contributing very little. The pattern was identified in OpenStreetMap (Budhathoki et al. 2010) and in patterns of geotagged photos. This pattern is exclusionary, as it highlights and rewards the participants who have more time and resources to contribute heavily to the system, while ignoring and marginalising other contributors.

These exclusionary aspects are amplified by demographic biases. Many of these systems are male-dominated, contributed to by highly educated and usually affluent members of society (Budhathoki et al. 2010) and their cultural practices are sometimes aggressive and misogynistic, thus creating further alienation (Cohen 2011). As Graham (2010) aptly demonstrated, the results of all these processes are in variable representations of places, languages and local interests. Notice that these social practices within the virtual communities that neogeography creates actively work against democratic practices and the software of the systems is designed to promote the strongest contributors while marginalising small-scale contributions.

Further exclusions happen not only due to the creation of systems that mainly focus on corporate interests (and values) in neogeographic technologies (Warf and Sui 2010) but also because 'epistemologies, vocabularies, and categories of data structures do not or cannot encompass the experiences, knowledge claims, and identities of some social groups or places' (Elwood 2008, p. 178).

In summary, the social, economic, structural and technical evidence should be enough to qualify and possibly withdraw the democratisation claims that are attached to neogeographic practices. The democratic vision offered is a 'cyberlibertarian' or 'technolibertarian' one (Winner 1997, Borsook 2000), which highlights 'radical individualism, enthusiasm for free market economy, disdain for the role of government, and enthusiasm for the power of business firms' (Winner 1997, p. 16) and does not strive to reach out to marginalised groups or try to accommodate diverse opinions.

Yet, while the evidence shows that the concept of democratisation is problematic in the praxis of neogeography, we still need to deal with its democratic potential. This is necessary to address the continued conceptualisation of digital exclusion as a problem that can be solved - for example in the discussion between Turner and Goodchild (Wilson and Graham this issue). We turn to this level of analysis in the next section.

\section{Hacking and the democratic potential of neogeography}

To address the potential of democratisation within neogeographic tools, we need to return to Feenberg's idea of deep democratisation, and the ability of ordinary citizens to direct technical codes and influence them so they can include alternative meanings and values. By doing so, we can explore the potential of neogeographic practices to support democratisation in its fuller sense. At the very least, citizens should be able to reuse existing 

reviewed and edited version of this article is published in Environment and Planning A 2013, 45(1), 55 - 69 doi:10.1068/a45184

technology and adapt it so it can be used to their own goals and to represent their own values. As the previous section demonstrated, the current corporatisation of the Web means that citizens cannot expect tools to emerge by themselves through the market, but need to create them.

To analyse this potential, I add to Feenberg's analysis of primary and secondary instrumentation a hierarchy of hacking, here understood as the ability to stretch the functionality and capabilities of a given system beyond those that are provided by its creators. The hierarchy is presented in Figure 2.

\begin{tabular}{|l|l|l|}
\hline Type & No. of participants & Issue for Neogeography \\
\hline Deep technical & & $\begin{array}{l}\text { Significant skills, negotiation } \\
\text { \& translation of knowledge }\end{array}$ \\
\hline $\begin{array}{l}\text { Shallow } \\
\text { technical }\end{array}$ & $\begin{array}{l}\text { Skills, user / programmer, } \\
\text { control over the application }\end{array}$ \\
\hline Use & $\begin{array}{l}\text { Knowledge of Web apps, } \\
\text { legitimacy of outputs, access } \\
\text { to data and software }\end{array}$ \\
\hline Meaning & $\begin{array}{l}\text { Outputs, legitimacy of } \\
\text { interpretation, overcoming } \\
\text { 'technophobia' }\end{array}$ \\
\hline
\end{tabular}

Figure 2 - Levels of hacking

There are four levels that are suggested here and are opened by a system: meaning, use, shallow technical and deep technical. They are explained, with examples that are relevant to the discussion of neogeography, below.

The first, and most popular, is 'meaning hacking'. Here, the participant is not making any change to the system or trying to intervene in its technical code, so its primary instrumentation remains untouched. The change to the system is done in its secondary instrumentation, through provision of new context and meaning to its application. This can happen when users reinterpret information that is provided to them online, and use a system that was created for one purpose for another; for example, when volunteers of Map Action, during their response to humanitarian call, find maps or geotagged photos on the Web and collect them to understand some aspects of the place to which they are going to deploy. The information is unlikely to have been uploaded to support the emergency response but, because it is available and accessible, it is ready to gain new use. Another 
form that was discussed above is 'geocaching' in which GPS receivers are used as part of leisure and play activity. The receiver is the same as the one that was designed for hiking, but its meaning is altered. This form of hacking is the most readily available to the majority of computer literate users, and is likely to happen frequently, without much thought. More sophisticated meaning hacking requires lateral thinking by the user, and an understanding that the information can be reused for their purpose and goals. Yet, if there is an obstacle here, it is conceptual - not technical. While this type of appropriation of tools is widely available, its impact is limited; for example, it is almost impossible for a marginalised group to galvanise enough support that will bring its activity to the level that it will appear first on search pages or in social media.

The second level of hacking is 'use hacking'. In this case, the participant is reusing some of the functionality of the system that was created with specific ideas in mind and translated to specific technical code (primary instrumentation), and is appropriating it for a new purpose: imbuing it with new meaning in the process and thus changing its original secondary instrumentation. Examples of this type of hacking are 'memory maps' in Flickr. In April 2005, Flickr added the ability to annotate photos by marking rectangular areas on them. The designers created this functionality probably to allow the system users to annotate photos by indicating names of those who appear in the photograph or note specific features. However, one of the users of Flickr, Matt Haughey, who also blogs (thus is among the few who are actively contributing to online systems), realised that he could take a screen shot of satellite imagery of the area in which he grew up in Google Maps, upload the image to Flickr (somewhat disregarding copyright issues) and use the annotation tools to mark specific locations on the image, attaching to them personal memories such as: 'My first girlfriend lived here ("Lisa"). I met her the summer between 7th and 8th grade when she moved in. We never kissed, and when school started I ignored her because she was in 7th and I was in 8th. I was an ass.' (Figure 3). He was quickly followed by other Flickr users and there are now over 650 memory maps on Flickr. This personal use of web mapping and photo sharing systems required some technical understanding, but not at a very high level. Interestingly, it was quickly noticed and endorsed by the official Flickr Blog as an acceptable practice.

This type of hacking is still open to a wider range of users, but requires technical knowhow. This is likely to be the most significant in terms of neogeography democratisation potential, as within many marginalised groups there are some people with some technical skills that will enable them to utilise tools in new ways. For example, the capability to use Google Earth in a way that assists local campaigns can be significant in providing easy access to information and tools. 

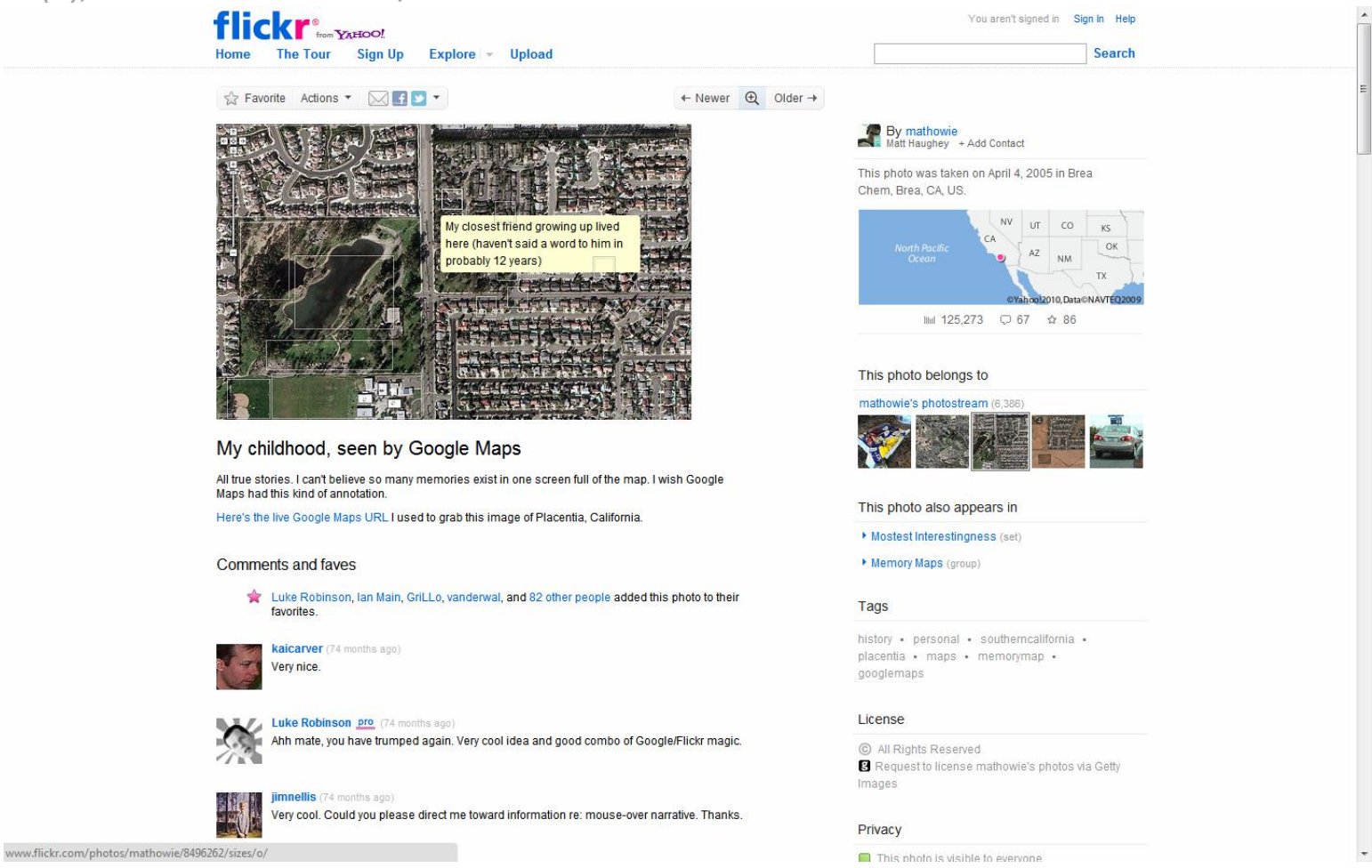

Figure 3 - Memory map in Flickr

The third level is 'shallow technical hacking', in which systems are reconfigured and organised to provide a new social meaning. Mashup, or the integration of information from multiple systems, is a good example of this. A few weeks after Google released their mapping service in 2005, Paul Radamacher developed a new site that merged information from the San-Francisco-based free small-ads website Craigslist with Google information in a site called HousingMaps (Tran, 2007). This process of combining information from several websites and sources to produce a new web service became more common. While Radamacher is highly technically capable (he holds a PhD in computer science) and was able to understand how Google code works and change it, later on, with the publications of Application Programming Interfaces (APIs), the creation of mashups became an easier task. The APIs are provided with code examples. This is important for people with some ability of scripting, which is the writing of short computer programs that deal with fairly simple tasks by reusing or adapting the existing code examples without a deep understanding of the technology. Such users can create new mashups and, therefore, offer new configurations of technology. Shallow hacking requires both the aptitude to manipulate computer code and a technical ability to do so. What is important is that, through this reconfiguration, it is possible to create new representations of places. When it is done without political or social understanding, as Miller (2006) records in the creation of Scipionus.com as a response to the Hurricane Katrina disaster, it is not surprising to find out that it has failed marginalised groups as Crutcher and Zook (2009) show. On the other hand, McConchie and Klinkenberg (2011) demonstrated counter mapping of the area of Vancouver in which the Winter Olympics were hosted. This was carried out through reconfiguration of the Google My Maps facility. This is a clear example, at this level, of some democratisation in the sense of increasing participation and bringing voices that are silenced through the official representation of the city. 
The final and fourth level is 'deep technical hacking'. It is the closest to Feenberg's 'deep democratisation' as it requires changes to the technical codes themselves and the creation of new systems that are capable of opening new political and social spaces. Sieber's (2004) call for the rewiring of GIS to achieve the goals of GIS/2 works at this level. The creation of OpenStreetMap as a way to allow the production of free geographic information that is accessible to anyone and for any purpose is another example. This level of hacking requires very significant technical knowledge in creating new geographic data collection tools, setting up servers and configuring database management systems. These skills are available to only a small technical elite within society. Thus, such intervention in technical codes is possible only to those who are involved in both primary and secondary instrumentation, and are deliberately using the technology to open up new opportunities, expressions and representations. Deep technical hacking can indeed lead to a deep democratisation of geographic information technologies, and the integration of users' concerns and needs in new systems. Examples of this are included in the community maps that are created at $\mathrm{UCL}$ (www.communitymaps.org.uk Ellul et al. 2009) where community engagement is part of the process of creating the maps and managing them. This participatory design of the maps allows the communities to express the issues that concern them through the use of neogeographic technologies. Another example is the creation of Map Kibera (www.mapkibera.org) in which OpenStreetMap was used to create the first detailed map of the largest informal settlement in Nairobi, which, like most informal settlements, was not mapped by official bodies. Thus, the act of creating the map is a political intervention in making the place visible and therefore the act of creating it goes beyond the practical humanitarian benefits of having a map.

The hacking hierarchy can be helpful in realising the democratisation potential of neogeography. It provides a way to unpack Elwood (2010, p. 352) observation that the geoweb almost certainly introduces new mechanisms of exclusion as, for instance, in the advantage afforded to those who have the coding skills to create their own 'mash ups' with open APIs, compared to those who can only view or contribute to such resources.' It is clear to see that, as we go up the scale, the level of intervention and change of technical codes required becomes more significant, and the number of people that have the necessary skills and knowledge, the interest in making the change and the time and resources to carry them through decreases. So, while the potential for 'meaning' hacking is open to almost any person who can access and use the Web (and this already exclude many), the impact of such action is most likely to be limited and local. The most significant interventions in neogeographic technical codes, such as those carried out by the activists that created Map Kibera, require not just the creation of new technologies but also working on the ground with the community and then with various aid organisations and the media to promote the work - the act of creating an alternative rationalisation of technology requires focused and sustained effort on both primary and secondary instrumentation. This also brings us back to the PGIS and critical GIS discussion about democratisation, and shows the need for technical intermediaries that will facilitate the process, while showing full commitment to inclusion and empowerment of the people that they work with. 


\section{Conclusions}

The analysis of the validity of the claims of democratisation in the context of neogeography shows that much caution is required in the use of the term. Even in its shallow form of potentially increasing access to technologies, it holds very limited ground as while, indeed, neogeography increased quantitatively the number of people that can access and use geographic information it is doing so within a sector of technology savvy, educated and well off and not in a universal way across the wider population. The main error in the core argument of those who promote it as a democratic force is the assumption that, by increasing the number of people who utilise geographic information in different ways and gain access to geographic technology, these users have been empowered and gained more political and social control. As demonstrated in this paper, neogeography merely opened up the collection and use of this information to a larger section of the affluent, educated and powerful part of society.

Moreover, the issue with neogeographic information and practices goes beyond who can use it. The control over the information is kept, by and large, by major corporations and the participant's labour is enrolled in the service of these corporations, leaving the issue of payback for this effort a moot point. Significantly, the primary intention of the providers of the tools is not to empower communities or include marginalised groups, as they don't represent a major source of revenue.

Feenberg's framework reminds us that all technology is political and not value neutral, and that politics and values are embedded into the technical codes of neogeography. Once these aspects are noticed, the true democratisation potential of neogeography can be explored and, on both empirical and analytical accounts, it is found wanting. As was the case with previous geographic information technologies, and as the body of research on critical and participatory GIS demonstrated, neogeography does have a democratisation potential in its fuller sense. It can be used to increase participation, empower marginalised groups and bring new voices that are unheard or ignored, if applied carefully and sensitively.

The analysis of the different levels of 'hacking', or altering a system from its original aim, is provided to frame the potentials and limits of neogeographic practices. While the lower levels of 'meaning hacking' or 'use hacking' have, indeed, been opened up by the emergence of neogeography (Haklay et al. 2008), their democratic potential is limited. The higher levels, where deep democratisation of technology is possible ('shallow technical hacking' and 'deep technical hacking'), require skills and aptitude that are in short supply and are usually beyond the reach of marginalised and excluded groups in society. They are even beyond the reach of most civic society organisations, since the specific technological elites that develop web technologies are notorious for their lack of philanthropy (Borsook 2000).

Therefore, to fulfil the democratisation potential of neogeographic practices, a concerted effort is required to integrate new groups in society in the design and development of technological objects and systems and an ongoing effort to reach out to those who are under-represented. To do that, we need to take into account the everyday geography of communities in streets, villages and slums and find ways to ensure that the technical codes 
of neogeography provide the space for the voices from these places are heard and represented.

\section{Acknowledgements}

I would like to thank the anonymous reviewers for their useful and constructive suggestions, which helped in improving this paper, as well as the people who have commented in the previous occasions in which I have discussed the core concepts of this paper, during the Royal Geographical Society (with the Institute of British Geographers - RGS-IBG) 2006 annual international conference, a seminar to the geography group of the Institute of Education, University of London in 2008, a seminar to the World University Network in 2008 and the participants of Mapping Change for Sustainable Communities event in 2008.

\section{References}

Batty, M., 1997, Virtual Geographies, Futures, 29(4/5), 337-352.

Bellamy-Foster, J., and McChesney, R.W., 2011, The Internet Unholy Marriage with Capitalism, Monthly Review, 62(10) http://monthlyreview.org/110301fostermcchesney.php

Borsook, P., 2000, Cyberselfish - a Critical Romp through the Terribly Libertarian World of High Tech, Little, Brown and Company: London.

Budhathoki, N.R., Haklay, M., and Nedovic-Budic, Z., 2010, Who are the Mappers and Why do they map in OpenStreetMap? State of the Map. The 4th Annual International OpenStreetMap conference. Girona, Spain. July 9-11.

Butler, D., 2006, The Web-Wide World, Nature, 439, 776-778.

Castells, M., 1996, The Rise of the Network Society ,Blackwell Publishers: Malden, MA.

Cohen, N., 2011, Define Gender Gap? Look Up Wikipedia's Contributor List, New York Times, $30^{\text {th }}$ January 2011, available http://www.nytimes.com/2011/01/31/business/media/31link.html? $\quad r=1$

Crutcher, M., and Zook, M.A., 2009, Placemarks and waterlines: Racialized Cyberscapes in Post-Katrina Google Earth, Geoforum, 40(4), 523-524.

Dobson, J., and Fisher, P.F., 2003, GeoSlavery. IEEE Society and Technology, 22(1), 47-52.

Doppelt, G., 2006, Democracy and Technology, in Veak, T.J. (Ed.), Democratizing Technology State University of New York Press: Albany, NY, 85-100.

Dusek, V., 2006, Philosophy of Technology: An Introduction, Wiley-Blackwell.

Ellul, C., Haklay, M., Francis, L., and Rahemtulla, H., 2009, A Mechanism to Create Community Maps for Non-Technical users, The International Conference on Advanced Geographic Information Systems \& Web Services - GEOWS 2009, Cancun, Mexico, 1-7 February.

Ellul, J., 1964, The Technological Society, Knopf: New York, NY.

Elwood, S., 2002, GIS use in Community Planning: a Multidimensional Analysis of Empowerment. Environment and Planning A, 34, 905-22. 
Elwood, S., 2008, Volunteered Geographic Information: Future Research Directions Motivated by Critical, Participatory, and Feminist GIS. GeoJournal 72(3/4), 173-183.

Elwood, S., 2009, Geographic Information Science: New Geovisualization Technologies Emerging Questions and Linkages with GIScience Research. Progress in Human Geography, 33(2): 256-263.

Elwwod, S., 2010, Geographic information science: emerging research on the societal implications of the geospatial web. Progress in Human Geography, 34(3), 349-357.

Feenberg, A., 1999, Questioning Technology, Routledge: New York.

Feenberg, A., 2002, Transforming Technology - a Critical Theory Revisited, OUP: New York.

Feenberg, A., 2006, Replies to Critics, in Veak, T.J. (Ed.), Democratizing Technology State University of New York Press: Albany, NY, 175-210.

Friedman, T.L., 2006, The World is Flat: A Brief History of the Twenty-First Century, Updated and Expanded Edition. Farrar, Straus and Giroux: New York.

Ghose, R., 2001, Use of Information Technology for Community Empowerment: Transforming Geographic Information Systems into Community Information Systems. Transactions in GIS 5, 141-63.

Ghose, R., 2007, Politics of scale and networks of association in public participation GIS Environment and Planning A 39(8) 1961-1980

Goodchild, M.F., 2007, Citizens as Voluntary Sensors: Spatial Data Infrastructure in the World of Web 2.0, International Journal of Spatial Data Infrastructures Research, 2, 24-32.

Graham, M., 2010. Neogeography and the palimpsests of place: Web 2.0 and the construction of a virtual earth. Tijdschrift voor economische en sociale, 101(4), 422436.

Haklay, M., Singleton, A., and Parker, C., 2008, Web mapping 2.0: the Neogeography of the Geoweb, Geography Compass, 2(6), 2011-2039.

Hargittai, E., 2002, Second Level Digital Divide: Differences in People's Online Skills, First Monday, 7(4) [online], Available from:

http://www.firstmonday.org/issues/issue7_4/hargittai/, Accessed: 1st August 2008

Harris, T.M., Weiner, D., Warner, T., and Levin, R., 1995, Pursuing Social Goals Through Participatory GIS: Redressing South Africa's Historical Political Ecology, in Pickles, J. (Ed.), Ground truth: the social implication of Geographic Information Systems, New York: The Guilford Press. 196-222.

Latour, B., 1993, We Have Never Been Modern, Harvard University Press: Cambridge, MA.

Latour, B., 1996, Aramis: or the Love of Technology, Harvard University Press: Cambridge, MA.

Leitner, H., Elwood, S., Sheppard, E., McMaster, R., and McMaster, S., 2002, Models for making GIS available to community organizations: Dimensions of difference and 
appropriateness. In Public Participation GIS, W. Craig, T. Harries and D. Weiner (eds.), London: Taylor and Francis: 37-52, 2002.

Lohr, S., 2011, Online Mapping Shows Potential to Transform Relief Efforts, New York Times, 28 March 2011

http://www.nytimes.com/2011/03/28/business/28map.html? r=2\&pag

Marx, L., 1999, Information Technology in Historical Perspective, In Schon, D., Sanyal, B., and Mitchell, W. J. (Eds.), High Technology and Low-Income Communities: Prospects for the Positive Use of Advanced Information Technology, MIT press: Cambridge, MA, 105-130.

McCall, M.K., 2003, Seeking good governance in participatory-GIS:a review of processes and governance dimensions in applying GIS to participatory spatial planning, Habitat International 27 (2003) 549-573.

McConchie, A., and Klinkenberg, B., 2011, Hybrid Counter-cartography: Google Maps and the Participatory Re-mapping of the Vancouver 2010 Winter Olympics. Paper presented at the Association of American Geographers 2011 Annual Meeting, Seattle, WA, April.

Miller, C.M., 2006, A Beast in the Field: The Google Maps Mashup as GIS/2, Cartographica. 41(3), 87-199.

Negroponte, N., 1995, Being Digital, Knopf: New York, NY.

Nielsen, J., 2006, Participation inequality: encouraging more users to contribute, Albertbox 9 October.

O’Reilly, T., 2005, What Is Web 2.0: Design Patterns and Business Models for the Next Generation of Software, Posted 30/09/2005. http://www.oreillynet.com/lpt/a/6228 [Accessed 24 June 2006]

O'Sullivan, D., 2006. Geographical information science: critical GIS, Progress in Human Geography, 30, 783-791.

Pickles, J. (Ed.), 1995a, Ground truth: the social implication of Geographic Information Systems, New York: The Guilford Press.

Pickles, J., 1995b, Conclusion: Towards an Economy of Electronic Representation and the Virtual Sign, in Pickles, J. (Ed.), Ground truth: the social implication of Geographic Information Systems, New York: The Guilford Press. 223-240.

PriceWaterhouseCoopers (PwC), 2009, Champions for Digital Inclusion - The Economic Case for Digital Inclusion, London.

Sawicki, D., and Craig, W., 1996, 'The democratization of data: bridging the gap for community groups' Journal of the American Planning Association 62:4 (Autumn 1996) 512-523

Scharff, R., and Dusek, V., 2002, Philosophy of Technology: The Technological Condition - An Anthology, Wiley-Blackwell. 


\section{5(1), 55 - 69 doi:10.1068/a45184}

Schroeder, P., 1996, Criteria for the design of a GIS/2, Specialists' meeting for NCGIA Initiative 19: GIS and Society, Summer 1996. http://www.spatial.maine.edu/ schroedr/ppgis/criteria.html

Sieber, R., 2004, Rewiring for a GIS/2, Cartographica 39(1), 25-39.

Sieber, R., 2006, Public Participation and Geographic Information Systems: A Literature Review and Framework. Annals of the American Association of Geographers, 96(3), 491-507.

Tran, T., 2007, Google Maps Mashups 2.0, Google Lat-Long Blog, posted 11/7/2007 http://google-latlong.blogspot.com/ [Accessed 2 November 2007]

Turner, A.J., 2006, Introduction to Neogeography. O'Reilly Media, Inc: Sebastopol, CA.

USDOC/NTIA, 1999, Falling Through the Net: Defining the Digital Divide, Washing D.C., 125 pp.

Veak, T.J., 2006, Democratizing Technology, State University of New York Press: Albany, NY.

Warf, B., and Sui, D., 2010, From GIS to neogeography: ontological implications and theories of truth, Annals of GIS, 16(4) 197-209.

Winner, L., 1997. Cyberlibertarian myths and the prospects for community. SIGCAS Comput. Soc. 27(3), 14-19. 
Haklay, M. (2013), Neogeography and the delusion of democratisation. The definitive, peerreviewed and edited version of this article is published in Environment and Planning A 2013, 45(1), 55 - 69 doi:10.1068/a45184 